\title{
APPLICATION OF CLOUD COMPUTING IN PROGRAMMING INTELLIGENT ELECTRIC NETWORKS IN PROSUMERS' HOUSEHOLDS
}

\author{
Marek Horyński ${ }^{1}$, Jacek Majcher ${ }^{1}$ \\ 1 Institute of Electrical Engineering and Electrotechnologies, Lublin University of Technology, Lublin, Poland, \\ e-mail:m.horynski@pollub.pl, j.majcher@pollub.pl
}

Received: 2016.08 .16

Accepted: 2016.09.26

Published: 2016.11.01

\begin{abstract}
Currently, cloud computing models are provided with increasing a number of new functionalities. The paper describes a laboratory model of intelligent KNX system which makes it possible to test the practical use of cloud computing in components programming for this system. The cloud computing elements were used for this purpose. Innovatory features of services transferred to the cloud computing models consists in the integration of advanced IT techniques and Internet technologies based systems with the users services, in this case with the management of an intelligent building system. The software ETS5 installed on workstation is another important component of the station being discussed.
\end{abstract}

Keywords: cloud computing, KNX, programming, network, prosumer.

\section{INTRODUCTION}

Nowadays, the conventional model is the most popular method of software use with an application installed on computers of all its users. Therefore, the purchase of a sufficient number of licenses and time consuming installation of software on each computer is necessary.

Currently, cloud computing model is provided with an increasing number of new functions. In new strategy for "unleashing potential of cloud computing in europe", ec determined activities leading to achievement of certain benefits i.e. 2.5 million new jobs in Europe and GDP annual growth in EU by 160 billion EUR (about 1\%) by 2020. The aim of this strategy is to expedite and optimize the process of unleashing potential of cloud computing in the whole economy.

Term "cloud computing" refers to storage of data (text files, photos, video files) and software - on computers situated in other locations - made accessible to users over the Internet, using a selected device (Chodźko 2011) (Czerwonka 2013) (Serafinowicz 2011). This solution is faster, cheaper and more secure than IT solutions located on site. Cloud computing technol- ogy is already used in many popular services e.g. Facebook, Spotify and webmail, but real economic benefits are possible in case of wider use of cloud computing solutions by entrepreneurs and public sector entities.

There are several models of cloud computing: SaaS (Software as a Service), collocation, IaaS (Infrastructure as a Service), PaaS (Platform as a Service), CaaS (Communications as a Service), $\mathrm{S}+\mathrm{S}$ (Software and Service), private, public, "dedicated" and "hybrid" cloud computing models.

SaaS model based upon interactive web application providing access to remote software becomes increasingly popular. The assumptions of SaaS model are as follows: a user pays sub-scriber fee for access to the application owned by SaaS provider. Since the beginning, applications are created in a manner enabling remote use by many clients; technical model ensures that applications are offered in shared hardware and program environment, specialized applications of SaaS provider are adapted to client's needs, who is fully aware of application offered by provider. Therefore, it is possible to reduce the size of clients' IT (Information Technology) department and to focus attention exclusively at ensuring uninter- 


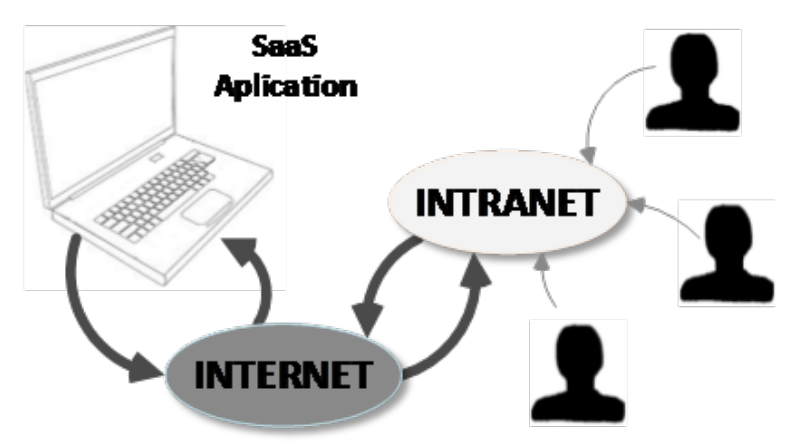

Fig. 1. SaaS model

rupted access to SaaS application (Benazzouz et al. 2014). The principle of SaaS model software use is illustrated in Fig. 1. SaaS offers interesting functions to users and providers.

Elimination of the necessity of installing the application on user's computeris favorablefortheuser - only standard web browser is needed. In a company using SaaS, any large IT department or external services are unnecessary; consequently, it is possible to cut support and service costs. The access to continuously updated software from any computer and place is also important. Backup copies of users' documents and data are also created by the provider.

Interesting opportunities are offered by SaaS model for the application provider who is not required to adapt the software to various hardware configurations, as web browser whose warrants correct support for network standards is used as user's application. Therefore, the number of potential problems associated with software use is limited. Furthermore, software provider maintains a complete control over application users. SaaS cloud computing reduced the piracy problem because the programs are accessible for registered users paying for the services provided (Wu et al. 2011). Consequently, software delivery on data carriers and potential theft is eliminated. OpenSource applications, which are distributed free of charge, are also offered in SaaS model in Poland. In the opinion of users, said applications are hard to maintain and their offer in SaaS is attractive. Their scope encompasses CMS (content management system), CRM (customer relationship management) systems and even on-line shops. The most popular SaaS software encompasses eProcurement, mobile trade, e-banking and e-commerce.

With the development of modern farms, attention should be paid to the growing demand for electricity. Recipients from rural areas who use the power of professional power stations are placed at the end of the transmission line. Distribution of energy over long distances entails heavy losses, which result in an increase in electricity prices. Such recipients are forced to seek alternative sources to meet the growing demand for energy. Because of a large up-front investment, production of energy from renewable sources without financial support is still less profitable than conventional sources. For this reason, EU member states pursue policies aimed at increasing the attractiveness of renewable energy sources for small farms for economic reasons. The possibility of using raw materials from farms and recycling waste to generate energy also speaks in favour of the implementation of this type of distributed generation. Despite regular reconstruction of the transmission network in rural areas, it is still not adapted to the requirements imposed by modern recipients. The main problems of the current network include:

- low voltage parameters;

- insufficient transformer stations of high and medium voltage;

- too long power lines, which are vulnerable to overload;

- peak power per unit farm is $2 \mathrm{~kW}$.

Maximum power which is supplied to households is unable to satisfy the demands of energy-intensive equipment and machinery. Factors hindering the development of large sources of renewable energy in the country, including long distances and poor state of the power grid, may at the same time be an impulse for the development of small distributed systems for individual households (Kacejko 2004) (Kacejko 2014) (Instytut na rzecz. 2011).

Creation of energy-independent households, which combined would form Autonomous Energy Regions may be a solution. An example of regional energy independence is the Kisielice Commune located in the Warmian-Masurian Voivodeship, which is Poland's first energy-independent municipality. Its area is 17,000 ha, and the population is about 6,600 . In 2014 it won the ManagEnergy 2014 competition organised by the European Commission.

Achieving the objectives pertaining to the use of renewable energy sources started in 2002. The municipality acquires its energy primarily from a wind farm consisting of 27 turbines with a total capacity of $40.5 \mathrm{MW}$. 
Since 2014, the production of energy has been supported by a farm biogas plant with a thermal capacity of approx. $1 \mathrm{MW}$ and electrical power of 0.99 MW. Currently, work is underway on the second phase of investments, the aim of which is to build a second wind farm. Six new turbines will be installed with a total capacity of $12 \mathrm{MW}$. The Kisielice Commune was presented at the conference "Heating and cooling in the European energy transition", held in Brussels in February 2015 (Instytut na rzecz. 2011).

What is also noteworthy is the promotion of energy-saving and energy-independent, autonomous buildings. In order to achieve a positive energy balance, such building uses many techniques minimising energy loss, and the most important goal is to produce energy from renewable sources. One source of additional energy are solar panels, aesthetically integrated into the façade of the building. In addition, solar technology is accessible, particularly as regards maintenance and repairs.

For this reason, it becomes important to develop research methods and tools useful for the development of integrated renewable energy microgrids. Universities and research centres play a special role in this process. The foundation of the Laboratory for Energy Efficient Building Systems is aimed at preparing the basis for the later development of micro- and intelligent networks with the participation of RES, by: conducting comprehensive monitoring of energy consumption and the potential of renewable energy sources to users also in rural areas, preparing tools for selection and optimisation of the use of renewable energy technologies in small microgrids, analyses enabling the design of a comprehensive decision support system for prosumer acting in microgrids.

The described model of computing cloud will be used for remote control of building automation based on the KNX system. Programming of this type of installations is performed by means of the ETS5 software.

\section{SYSTEMS PROGRAMMING IN ETS5 PROFESSIONAL ENVIRONMENT}

In recent years, the number of intelligent building systems users has increased (Granzer et al. 2006). Their most important feature is the necessity of activating devices in order to enable operation in the building system.
In the case of popular KNX open system (KNX it is the association which is the owner of the worldwide standard for home and building control), this necessity encompasses the assignment of physical addresses to devices determining their location in the system and parameterization i.e. selection of parameters essential for the system programmer and user and creation of logic connections between devices in the building. Specialized software is necessary for afore-mentioned activities (Parol 2007) (Horyński 2008).

Man - control system communication, i.e. HMI (Human-Machine Interface) (Chodźko 2011), consists in bilateral exchange of information concerning the specified process. On operator's end, this task consists in operation of controlled object and controlling system and their parameterization. Operation means all types of activities associated with system functioning i.e. devices status change (e.g. starting, shut-down), operation mode change (e.g. switchover from manual to automatic mode) and activities performed to prevent failures in emergency cases. Control system parameterization consists in parameters change in a currently controlled process (e.g. temperature, pressure), production parameters change (e.g. number of working cycles ) or protections settings change (e.g. change of limit values or alarm system time delay). Both activities i.e. operation and parameterization can be performed if the operator knows the system status. This information is obtained through visualization process (Chodźko 2011).

To program the bus devices, you must have dedicated software to program these devices. Bus devices operating in the KNX standard can be programmed by the ETS tool (Engineering Tool Software). The program is available free of charge on the manufacturer's website (free version has limited functionality). To program the bus devices, you must have dedicated software to program these devices. Bus devices operating in the KNX standard can be programmed by the ETS tool. The program is available free of charge on the manufacturer's website (free version has limited functionality). Devices programming process is the phase required after successfully created design. This process is extremely simplified in the case of ETS5 program and consists in selection of "Starting" and "Programming" command from menu. Programming progress visualization is triggered by clicking; commands to depress test pushbuttons are displayed on module 
in proper intervals to address and load executable program. The following elements were used in the test stand:

- push bush triton 6327;

- binary output AT/S 4.6.2;

- weather station WZ/S 1.1.

\section{WLAN NETWORK CONFIGURATION IN INTELLIGENT ELECTRICAL SYSTEMS LABORATORY}

The case discussed herein is associated with programming of remote access to intelligent system in Intelligent Electrical Systems Laboratory. Correct functioning of WLAN network is required to perform this task. Therefore, the access point i.e. router operating in IEEE 802.11 (Institute of Electrical and Electronics Engineers) standard should be configured first (Chodźko 2011).

TP-LINK WR340g router was used in design. Its correct configuration consists in connection of one of four inputs of WLAN network with router using twisted pair. Using browser enter the default gateway address (192.168.1.1) into address field. After correct connection the authentication form containing default login and password (admin) is displayed.

After logging in, choose Wireless and Wireless Settings tag. -On the opened subpage, choose WEP key format as ASCII and "128 bit" item from "Key Type" drop down menu. Enter the desired password into "WEP key" field; finally se- lect "Key Selected" field and save settings using "Save" pushbutton. Figure 3 illustrates typical IP addresses for individual devices in WLAN network. After wireless network configuration, perform the network authentication from computer level and using device with touch screen.

The method and effectiveness of user interface creation is essential for a successful implementation of projects associated with intelligent systems status visualization. Cloud computing element called SaaS (Server as a Software - Server as a service) is used in the case of OpenRemote. Using easy-to-operate creator, the user can create an interface from the ground up and assign specified functionality. After exporting this environment into cloud computing layer, problems associated with installation or dependence on specified architecture of operating system disappear. Web browser and current version of JRE (Java Runtime Environment) are sufficient for system operation.

\section{APPLICATION DESIGNING - OPENREMOTE DESIGNER}

"Thin Client" and "fat Client" mechanisms are encountered when designing remote management of an intelligent system and its visualization. "Thin Client" is a computer or computer terminal provided with Client software and supporting application created in Client - server architecture. The special feature of this solution is independence on supported server application and low processing power demand.

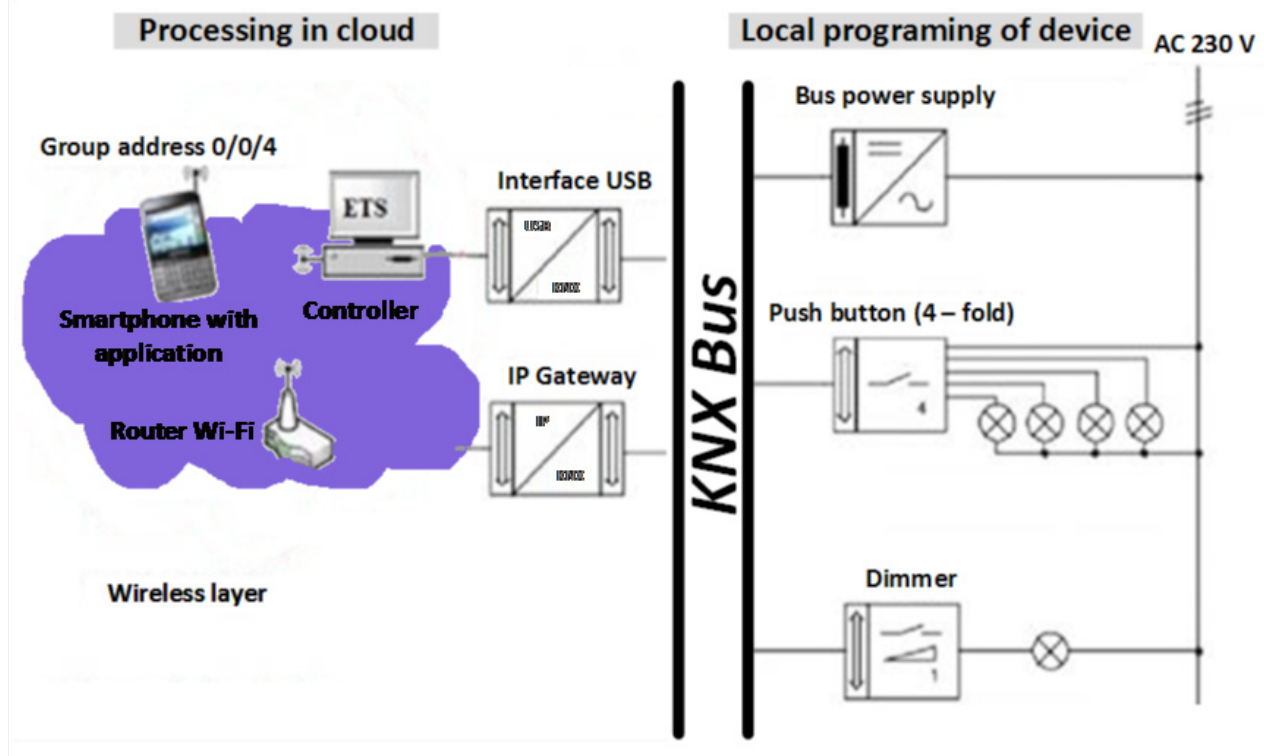

Fig. 2. Network protections configuration end (Chodźko 2011) 


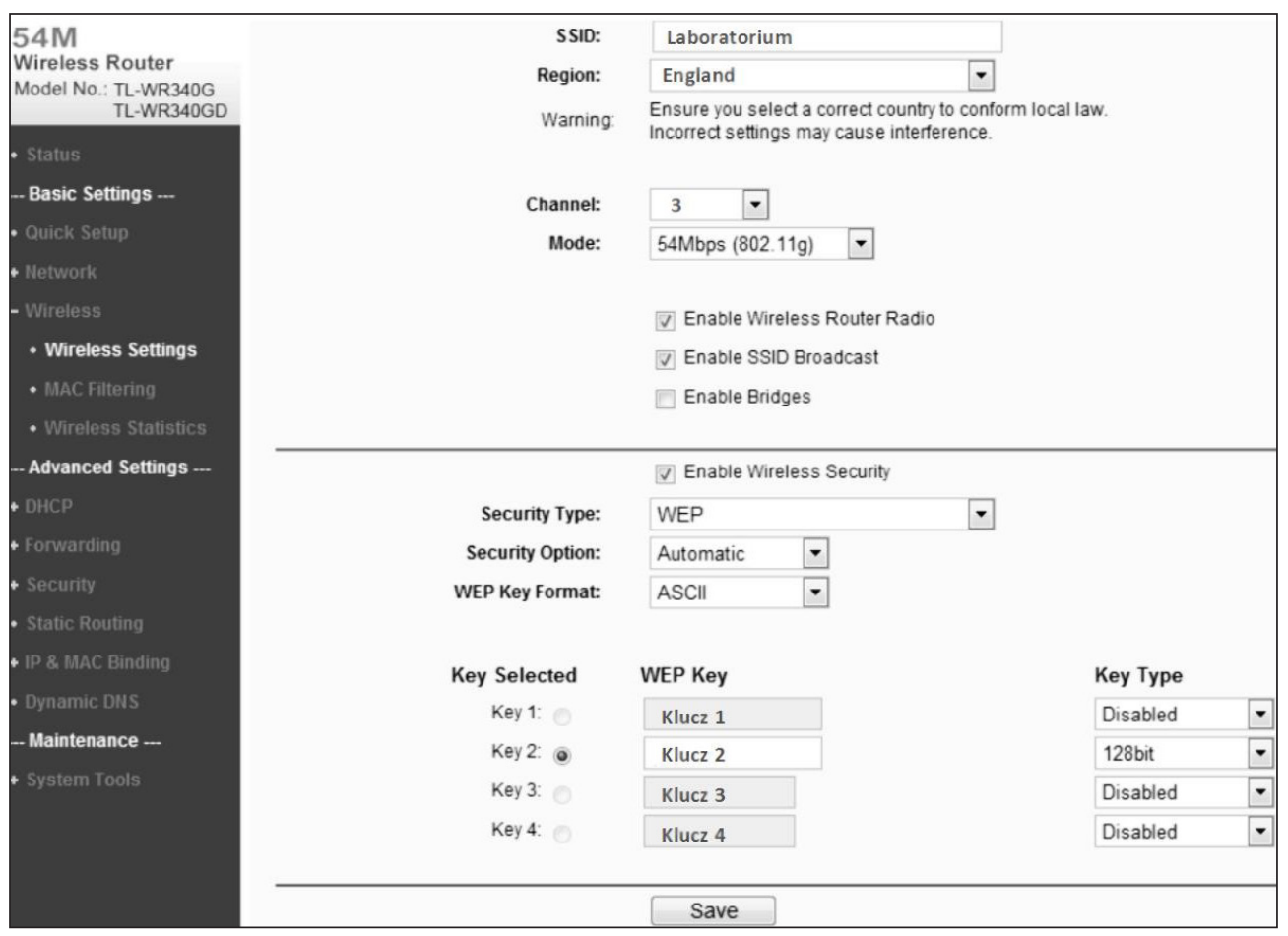

Fig. 3. IP addresses in LAN network

By now, solutions typical for "fat Client" mechanism were more frequently used by KNX systems programmers. "Fat Client" mechanism relates to user's workstation equipped with complete peripherals set, operating system and applications. Use of ETS5 program and applications of devices installed in the course of system application or system parameters change is an example. In this case utility programs are carried out in direct and autonomous mode on workstation performing data processing and data exchange with the user and other computers. Data are stored on a server.

Creation of graphical user's interface is the central point of application enabling remote control of intelligent system, presented previously. This task can be performed by means of a tool accessible from OpenRemote Designer. OpenRemote is an integration platform of commercial software, dedicated to building automation. This tool allows to create graphic panels carrying out the remote control process. This allows visualisation of processes as well as remote control. Functions are available when an account is created under the open license OpenRemote. Following account registration and confirmation by activating E-mail, logging panel is accessible to user.

An application containing animated switch corresponding to „Push button” function in KNX standard was created to meet its needs. In accordance with assumptions included in system design prepared in ETS5 program, the above-mentioned switch was assigned to $0 / 0 / 4$ address group which contains communication objects responsible for telegrams transmission from dimmer and binary input / output. Creation of interface application consists of the following phases:

- adding device performing communication gate role in KNX system;

- specifying module parameters in accordance with columns specified in form displayed in OpenRemote Designer dialog box;

- creating three commands operating on 1 bit DPT 1.001 data type: switch on, switch off, status. In the course of command configuration, specify the group address for KNX system element to which the command will refer.

In order to create virtual switch using touch panel, one needs to remember to create a sensor detecting changes when the screen is depressed. This problem is resolved in OpenRemote Designer environment using two structures. The first structure "Switch" represents the switch as object operating on commands assigning controlled object status. The second structure - "Sensor" is responsible for status change representation of the switch after pushbutton is depressed on touch 
panel. The both functionalities support each other and interface graphics.

In order to create sensor, choose Add sensor" from „new Device” elements window, write its name into an open form, choose previously defined STATUS command and the type of structure to be supported from bottom list at „Type" item (Fig. 4). When „Submit” pushbutton is depressed, new sensor is added to IP gate structures list.

Integration of all elements by means of „Switch" structure is the final phase in functional interface layer creation. After dialog box is displayed, commands are selected and the sensor is connected after its selection on list, it is possible to proceed to the next and most simple phase of interface designing. Figure 5 shows a laboratory model of the KNX system, controlled via SaaS.

Application controller environment is fully configured and running of this application commences on a smartphone. The first step of application running process is the running of application controller on laboratory stand PC unit. Therefore, start the system terminal and batch file application: openremote.bat with ,run" parameter. Successful initialization of controller application is associated with running of application server accessible via http. The user should go to address http://localhost:8080/controller/, in browser on computer with running controller and log in remotely to account created previously on OpenRemote server. Then, synchronization should be carried out to ensure automatic copying of graphical interface created with functional layer to running server. Now, it is possible to run application on a smartphone. Then choose virtual panel from a list displayed after application selection. After its name is selected, a panel is loaded commencing signals watching from touch screen.

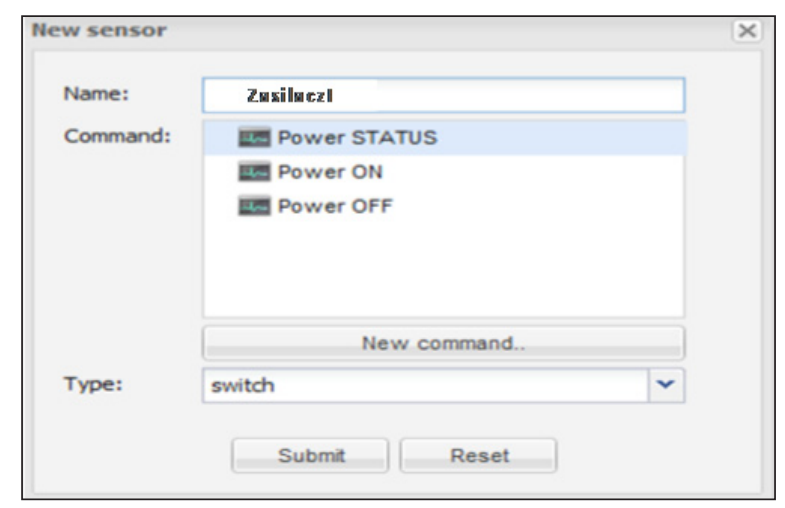

Fig. 4. Add new sensor to device (Chodźko 2011)

\section{CONCLUSIONS}

The paper presents the possibility of remote programming in building automation on the example of the KNX system. This solution allows remote control of the operation of each installation without the need for dedicated software in the visualisation of building automation. An additional advantage of the present solution is the ability to remotely control various types of installations in large sites and mutual communication of individual subnets. The present solution can be applied in smartphones or tablets and can be desirable in the case of the necessity of integrating many intelligent building systems in radio signal broadcasting zone.

Additional protections are necessary to ensure system safety in line with regulations concerning privacy protection, necessity of encryption and storage of data for jurisdiction needs. Close cooperation with cloud computing service provider is essential, e.g. creation of backup copies, data recovery, monitoring and reactions to hack attempts. Furthermore it is necessary to create data transfer mechanisms between conventional structure and cloud computing, cloud computing computers and various service providers.

Another issue worth considering, even as separate study, is the possibility of using wireless layer as infrastructure connecting lines or areas. This solution has advantages and disadvantages but it is a very interesting proposal because the telegrams flow by radio within one system, as well as between two systems with independent power supply can be ensured. Significant improvement is possible in the case of IEEE 802.11 protocol or much more energy efficient 802.15.4 (Zigbee - is the wireless language) (Chodźko 2011) (Lee, Hong 2009), except for the obvi-

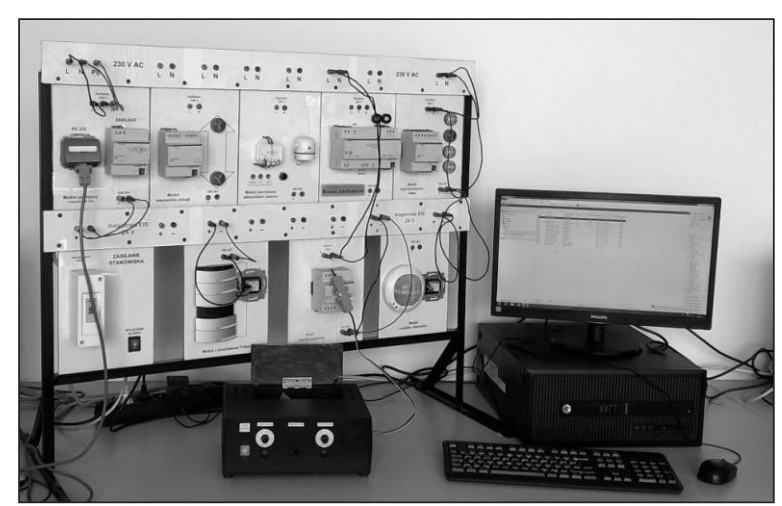

Fig. 5. The laboratory stand for configuring KNX Automation using OpenRemote 
ous aspects of communication speed between subgroups also in long distance communication. Moreover, it is possible to export connections using public addresses for web gates of Wi-Fi access points to Internet network level. Capabilities of virtual panel can be increased very easily i.e. by adding slider and appropriate parameters to settings of dimmer communication object using ETS environment. Other elements e.g. binary outputs / inputs can be also used.

Using proposed local network based upon IEEE 802.11 standard, it is very easy to attach other types of devices for which the applications were created to load graphical panels e.g. smartphones, or tablets, PC class notebooks with wireless network cards.

Another interesting solution is the application of public address for access point gate. In such a case, remote access is available from any location within global Internet network.

In the coming years we can expect further development of technologies related to renewable energy sources. This is due to the benefits provided for both local communities, increasing the level of energy security, as well as environmental benefits, primarily reducing emissions of carbon dioxide.

\section{REFERENCES}

1. Benazzouz Y., Munilla C., Gunalp O., Gallissot M. \& Gurgen L. 2014. Sharing user IoT devices in the cloud. [In:] Internet of Things (WF-IoT), 2014 IEEE World Forum.

2. Chodźko Sz. 2011. Zastosowanie komunikacji bezprzewodowej $\mathrm{w}$ inteligentnych systemach bu- dynków. Projekt stanowiska dydaktycznego. Praca magisterska. Politechnika Lubelska. (in Polish).

3. Czerwonka P. 2013. Chmura obliczeniowa jako rozwiązanie dla małych osd - możliwości i zagrożenia. Rynek Energii 1(104) (in Polish).

4. Dziamski P., Kamińska M., Michałowska-Knap K., Wiśniewski G. 2011. Energetyka rozproszona, Wyd. Fundacja Instytut na rzecz Ekorozwoju (in Polish).

5. Granzer W., Kastner W., Neugschwandtner G., Praus F. 2006. A modular architecture for building automation systems, Wien

6. Lee W.S. \& Hong S.H. 2009. Implementation of a KNX-ZigBee gateway for home automation. In Consumer Electronics, 2009. ISCE'09.

7. Parol M. i in. 2007. Monitoring i zdalne sterowanie instalacjami KNX za pośrednictwem Internetu. Przegląd Elektrotechniczny, 7-8, 19-23 (in Polish).

8. Horyński M. 2008. Instalacje elektryczne EIB $\mathrm{w}$ inteligentnym domu - komunikacja bezprzewodowa. Przegląd Elektrotechniczny, No. 3, 105-107 (in Polish).

9. Kacejko P. 2004. Generacja rozproszona w systemie elektroenergetycznym. Wyd. Politechniki Lubelskiej (in Polish).

10. Kacejko P. i in. 2014. Prosument - przyjaciel, wróg czy tylko hobbysta? Rynek Energii, 5, 83-89 (in Polish).

11. Serafinowicz A. 2011. Cloud computing, czyli chmury obliczeniowe. Nie błądzić w chmurach. PCLab 2011 (in Polish).

12. Wu L., Garg S.K., \& Buyya R. 2011. SLA-based resource allocation for software as a service provider (SaaS) in cloud computing environments. In Cluster, Cloud and Grid Computing (CCGrid), 11th IEEE/ACM International Symposium. 